\title{
Fuzzy-Logic Analysis of the FDR Data of a Transport Aircraft in Atmospheric Turbulence
}

\author{
C. Edward Lan ${ }^{1}$ and Ray C. Chang ${ }^{2}$ \\ ${ }^{1}$ Department of Aerospace Engineering, University of Kansas, KS, \\ ${ }^{2}$ Department of Aviation Mechanical Engineering, \\ China University of Science and Technology, \\ USA \\ Taiwan (R.O.C.)
}

\section{Introduction}

The aerodynamics of a jet transport in severe atmospheric turbulence, in particular involving plunging motion, is complex in that unsteady aerodynamic effects are significant and not well known. For instance, the aircraft response may lag behind the change in angle of attack and/or control surface deflections. Because of the change in angle of attack, the wing vortex wake may be pulsating. Coupled with the aircraft motion, the pulsating vortex wake would significantly affect the tail aerodynamics and hence, the aircraft stability and control characteristics. These are just a few possible phenomena in aircraft response to be identified. Unfortunately, these aerodynamic characteristics cannot be identified with existing ground testing techniques. Therefore, at present the only option to estimate the aircraft aerodynamic characteristics in severe atmospheric turbulence is to analyze the data from Flight Data Recorders (FDR). Traditional methods of system identification in aerodynamics, such as the maximum likelihood method (MMLE) (Maine \& Iliff, 1986), the least-square or the stepwise regression method (Klein, 1981), or the Extended Kalman Filter (EKF) (Minkler \& Minkler, 1993; Gelb 1982), have not been demonstrated to be applicable to estimating the unsteady aerodynamics based on these FDR data. Therefore, a more robust model identification technique would be needed. In addition, the established aerodynamic models should be directly usable in flight simulation. To satisfy these goals, the Fuzzy Logic Modeling (FLM) technique is adopted in the present application. The technique used here has been applied to model identification of a fighter aircraft from flight test data (Wang, et al. 2001; Wang, et al. 2002); aerodynamic estimation of transport aircraft from Flight Data Recorder (FDR) data (Lan \& Guan 2005; Weng, et al. 2008; Chang, et al. 2009); identification of uncommanded motions from wind-tunnel dynamic free-to-roll test data (Lan, et al., Jan. 2008; Lan, et al., May 2008); and non-aerodynamic problems with the FDR data (Lee \& Lan 2003; Lan, et al. 2006), just to name a few.

In the following, the present fuzzy logic algorithm will be described in some detail. It follows with some simple verification examples in Section 3. In Section 4, application of the 
FLM algorithm in aerodynamic model identification for a jet transport in severe atmospheric turbulence will be described in detail. Unsteady aerodynamics will be emphasized. Conclusions will follow in Section 5.

\section{Fuzzy logic modeling}

The general idea of the FLM technique is to set up the relations between system input and output variables. There are two approaches in the FLM technique. One is the fuzzy set approach, involving fuzzy sets, membership functions, weighting factors, and the if-then fuzzy rules (Zadeh 1973). The process involves three stages: fuzzification, fuzzy rule inference and defuzzification. The second approach is the internal function approach, involving the internal functions, membership functions, and the output cells (Takagi \& Sugeno 1985). The same three stages mentioned above can also be identified. Since the first approach does not provide continuous derivatives needed in aerodynamics, the second approach will be utilized in the present paper.

Basically, the present FLM algorithm represents a multi-dimensional, nonlinear interpolation scheme without requiring explicit functional forms between the input and output variables. In application, complex motions or relations involving many variables can be treated. Conceptually, each motion variable is divided into a number of ranges in which values of the membership functions are assigned. Each combination of membership functions, one from each motion variable, constitutes a fuzzy cell. Each fuzzy cell contributes to the prediction of the value of outcome equal to its internal function with an associated weighting factor. The latter represents an assembly of the membership grades of all variables. The final prediction of outcome is equal to the weighted average of contributions of all fuzzy cells. This overview will be repeated later by way of equations or formulas.

Two main tasks are involved in the present FLM process. One is the identification of the coefficients of the internal functions. The other one is structure identification to identify the optimal structure of fuzzy cells of the model, in other words, the optimal number of membership functions for each variable. Details of fuzzification, fuzzy rule inference and defuzzification stages in the present FLM technique are described in the following (Wang, et al. 1998, 2001, 2002).

\subsection{Fuzzification}

In this stage, many internal functions are defined to cover the ranges of the influencing variables (i.e. input variables). The ranges of the input variables are all transformed into the domain of $[0,1]$. The membership grading also ranges from 0 to 1.0, with "0" meaning no effect from the corresponding internal function, and "1" meaning a full effect. These internal functions are assumed to be linear functions of input variables as follows:

$$
P^{i}=y_{i}\left(x_{1}, x_{2}, \cdots, x_{r}, \cdots x_{k}\right)=p_{0}^{i}+p_{1}^{i} x_{1}+\cdots+p_{r}^{i} x_{r}+\cdots p_{k}^{i} x_{k}
$$

where $p_{r}^{i}, r=0,1,2, \ldots, k$, are the coefficients of internal functions $y_{i}$, and $k$ is number of input variables; $i=1,2, \ldots, n$, and $n$ is the total number of fuzzy cells.

The recorded data in FDR, such as flight altitude $(h)$, calibrated airspeed (CAS), angle of attack $(\alpha)$, accelerometer readings $\left(a_{x}, a_{y}\right.$, and $\left.a_{z}\right)$, and Euler angles $(\theta, \phi$, and $\psi)$, etc is chosen 
as the variables in the compatibility analysis and eventually forming the data for specific fuzzy models. In the present Chapter, $y_{i}$ is defined to be an estimated aerodynamic coefficient of force or moment, and $x_{r}$ are the variables of the input data. The numbers of the internal functions (i.e. cell's numbers) are quantified by the total number of membership functions (see below).

The values of each fuzzy variable, such as the angle of attack, are divided into several ranges, each of which represents a membership function with $A\left(x_{r}\right)$ as its membership grade. One membership function from each variable constitutes a fuzzy cell. For the $i^{\text {th }}$ cell, the corresponding membership grades are represented by $A_{r}^{i}\left(x_{r}\right), r=1,2, \ldots, k$. In other words, the membership functions allow the membership grades of the internal functions for a given set of input variables to be assigned. For a given system with input variables $x_{1}, x_{2}, \cdots, x_{r}, \cdots x_{k}$ of one data point, the recorded values of each input variables are normalized by using $\left(x_{r}-x_{r, \min }\right) /\left(x_{r, \max }-x_{r, \min }\right)$ to transform them into the ranges of $[0,1]$. The range, $\left(x_{r, \max }-x_{r, \min }\right)$, represents the scaling factor and usually is assumed to have a larger range than what actually appears in the data with numerous data points to be more generally applicable for the resulting model. In the present application in aerodynamics, it is empirically assumed to be 1.8 times larger. Generally, overlapped straight lines, triangles or parabolas are frequently the shapes used to represent the grades.

The membership functions partition the input space into many fuzzy subspaces, which are called the fuzzy cells. The total number of fuzzy cells is $n=N_{1} \times N_{2} \times \cdots \times N_{r} \times \cdots \times N_{k}$. For a variable $x_{r}$, the number of membership function is $N_{r}$. Each fuzzy cell is in a different combination from others formed by taking one membership function from each input variable.

Let $N$ be the number of membership functions and $j$ be the index for the $j$-th membership functions. Then the membership grades for triangular and parabolic shapes can be described as follows:

\subsubsection{Triangular membership functions}

1) $N=2$ :

$$
\begin{aligned}
& A\left(x_{r}\right)=x_{r}, \quad j=1 \\
& A\left(x_{r}\right)=1-x_{r}, j=2
\end{aligned}
$$

2) $\mathrm{N} \geq 3:$

For $j=3$ to $N-m$, where $m$ is equal to the greater number of 0 and integer of $(N-2) / 2$ :

$$
\begin{aligned}
& \qquad A\left(x_{r}\right)=x_{r} / d_{u}, \quad 0 \leq x_{r} \leq d_{u} \\
& \qquad\left(x_{r}\right)=\left(1-x_{r}\right) /\left(1-d_{u}\right), \quad d_{u} \leq x_{r} \leq 1 \\
& \text { where } d_{u}=\Delta x_{1}^{*}(j-2), \text { and } \Delta x_{1}=1.0 /(N-m-1) \text {. } \\
& \text { For } j \geq N-m \\
& A\left(x_{r}\right)=\left(d_{d}-x_{r}\right) / d_{d}, \quad 0 \leq x_{r} \leq d_{d} \\
& A\left(x_{r}\right)=\left(d_{d}-x_{r}\right) /\left(d_{d}-1\right), \quad d_{d} \leq x_{r} \leq 1 \\
& \text { where } d_{d}=\Delta x_{2}^{*}(j-N+m), \text { and } \Delta x_{2}=1.0 /(m+1) \text {. }
\end{aligned}
$$




\subsubsection{Parabolic membership functions}

1) $N=2$ :

$$
\begin{aligned}
& A\left(x_{r}\right)=x_{r}, \quad j=1 \\
& A\left(x_{r}\right)=1-x_{r}, j=2
\end{aligned}
$$

2) $N \geq 3$ :

2)/2:

For $j=3$ to $N-m$, where $m$ is again equal to the greater number of 0 and the integer of $(N-$

$$
\begin{aligned}
& A\left(x_{r}\right)=-x_{r}^{2} / d_{u}^{2}+2 x_{r} / d_{u}, 0 \leq x_{r} \leq d_{u} \\
& A\left(x_{r}\right)=-\left(x_{r}^{2}-2 d_{u} x_{r}+2 d_{u}-1\right) /\left(1-2 d_{u}+d_{u}^{2}\right), d_{u} \leq x_{r} \leq 1
\end{aligned}
$$

where $d_{u}=\Delta x_{1}^{*}(j-2)$, and $\Delta x_{1}=1.0 /(N-m-1)$.

$$
\begin{aligned}
& j>N-m \\
& A\left(x_{r}\right)=x_{r}^{2} / d_{d}^{2}-2 x_{r} / d_{d}+1.0,0 \leq x_{r} \leq d_{d} \\
& A\left(x_{r}\right)=\left(x_{r}^{2}-2 d_{d} x_{r}+d_{d}^{2}\right) /\left(1-2 d_{d}+d_{d}^{2}\right), d_{d} \leq x_{r} \leq 1
\end{aligned}
$$

where $d_{d}=\Delta x_{2}^{*}(j-N+m)$, and $\Delta x_{2}=1.0 /(m+1)$.

The membership functions are illustrated in Fig. 1 for triangular shapes and Fig. 2 for parabolic shapes. In Fig. 1, although the membership functions are continuous functions, there are discontinuities in slopes at some points. However, differentiation of membership
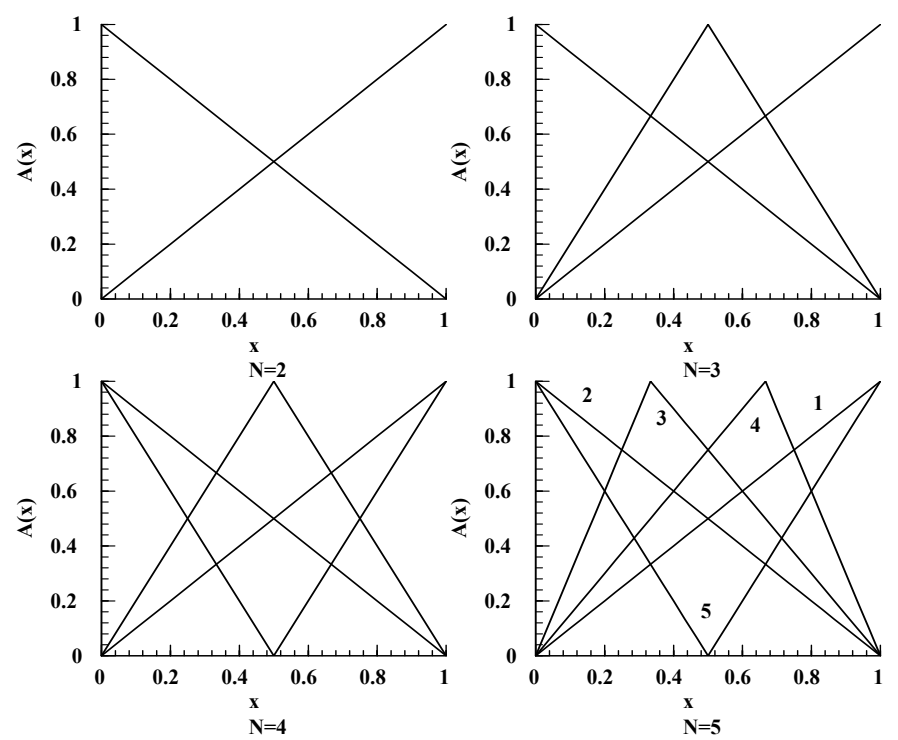

Fig. 1. Triangular membership functions 
functions is not performed in estimating derivatives. In the present application, aerodynamic derivatives are all estimated with a central difference scheme, which will be presented later. Because overlapped triangular membership function is simple and involves less computing time, it is the method to represent the grades of membership functions in the present FLM technique. Comparison of computed results based on these two types of membership function will be illustrated later.
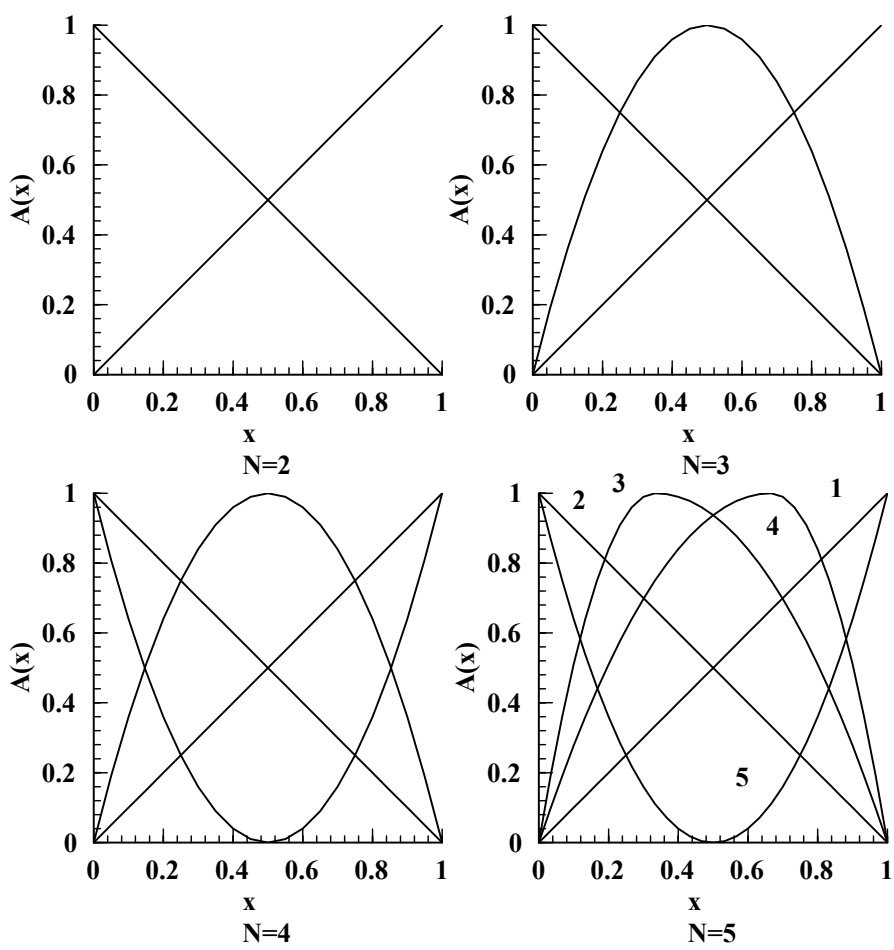

Fig. 2. Parabolic membership functions

\subsection{Fuzzy rule inference}

A fuzzy cell is formed by taking one membership function from each variable, as indicated earlier. The total number of cells is the number of possible combinations by taking one membership function from each input variable. For every cell, it has a fuzzy rule to guide the input and output relations. For the $\mathrm{j}^{\text {th }}$ data point, the rule of the $i^{\text {th }}$ cell is stated (Wang, et al. 1998) as:

if $x_{1, j}$ is $A_{1}^{i}\left(x_{1, j}\right)$, and if $x_{2, j}$ is $A_{2}^{i}\left(x_{2, j}\right), \ldots$ and if $x_{k, j}$ is $A_{k}^{i}\left(x_{k, j}\right)$ for the jth data point, then the cell output is equal to its internal function:

$$
P^{i}\left(x_{1, j}, x_{2, j}, \cdots, x_{r, j}, \cdots x_{k, j}\right)=p_{0}^{i}+p_{1}^{i} x_{1, j}+\cdots+p_{r}^{i} x_{r, j}+\cdots p_{k}^{i} x_{k, j}
$$


where $i=1,2, \ldots, n$ the index of the cells, $n$ is the total number of cells of the model; $P^{i}\left(x_{1, j}, x_{2, j}, \cdots, x_{r, j}, \cdots x_{k, j}\right)$ is the internal function with parameters $p_{0}^{i}, p_{1}^{i}, \ldots, p_{r}^{i}, \ldots p_{k}^{i}$ to be determined, and $A_{k}^{i}\left(x_{k, j}\right)$ denotes the membership grade for $x_{k, j}$. Each function covers a certain range of input variables.

\subsection{Defuzzification}

In each fuzzy cell, the contribution to the outcome (i.e. the cell output) is based on the internal function, Eq. (2.2). The final prediction of the outcome is the weighted average of all cell outputs after the process of reasoning algorithm. Because of this weighting among many factors over large ranges of possibilities, the word "fuzzy" is derived to describe the method. However, its prediction is never "fuzzy". The output is estimated by the center of gravity method. For the $j^{\text {th }}$ input $\left(x_{1, j}, x_{2, j}, \ldots, x_{r, j}, \ldots, x_{k, j}\right)$, the output is as follows:

$$
\hat{y}_{j}=\frac{\sum_{i=1}^{n} \operatorname{product}\left[A^{i}\left(x_{1, j}\right), \cdots, A^{i}\left(x_{k, j}\right)\right] p^{i}}{\sum_{i=1}^{n} \operatorname{product}\left[A^{i}\left(x_{1, j}\right), \cdots, A^{i}\left(x_{k, j}\right)\right]}
$$

In Eq. (2.3) product $\left[A^{i}\left(x_{1, j}\right), \ldots, A^{i}\left(x_{k, j}\right)\right]$ is the weighted factor of the $i$ th cell; and the index $j$ of the data set, where $j=1,2, \ldots, m$, and $m$ is the total number of the data records; and the "product" stands for product operator of its elements in this Chapter.

\subsection{Parameter identification}

Given a set of membership functions for each input variable, the unknown coefficients of the internal functions are determined by using the Newton gradient-descent method. The accuracy of the established aerodynamic model through the fuzzy-logic algorithm is estimated by the sum of squared errors (SSE) and the squared multiple correlation coefficients $\left(R^{2}\right)$ :

$$
\begin{array}{r}
S S E=\sum_{j=1}^{m}\left(\hat{y}_{j}-y_{j}\right)^{2} \\
R^{2}=1-\frac{\left\{\sum_{j=1}^{m}\left(\hat{y}_{j}-y_{j}\right)^{2}\right\}}{\left\{\sum_{j=1}^{m}\left(\bar{y}-y_{j}\right)^{2}\right\}}
\end{array}
$$

In Eqs. (2.4) and (2.5), where $\hat{y}_{j}$, the output of the fuzzy-logic model at data point $j$, is estimated by Eq. (2.3); $y_{j}$ is the data point used for the model training at point $j ; \bar{y}$ is the mean of the sample data, and $\mathrm{m}$ is the total number of data points. The model training is to determine the unknown coefficients of the internal functions, $\mathrm{pr}_{\mathrm{r}}^{\mathrm{i}}$, by maximizing the value of $R^{2}$. These coefficients are determined by the following iterative formula to minimize the sum of squared error (Eq. 2.4): 


$$
\begin{gathered}
p_{r, t+1}^{i}=p_{r, t}^{i}-\alpha_{r} \frac{\partial(S S E)}{\partial p_{r}^{i}} \\
\frac{\partial(S S E)}{\partial p_{r}^{i}}=2 \sum_{j=1}^{m}\left(\hat{y}_{j}-y_{j}\right) \frac{\partial \hat{y}_{j}\left(x_{1, j}, \ldots, x_{k, j}, p_{r}^{i}, \ldots, p_{k}^{n}\right)}{\partial p_{r}^{i}} \\
\frac{\partial \hat{y}_{j}}{\partial p_{r}^{i}}=\frac{\operatorname{product}\left[A_{1}^{i}\left(x_{1, j}\right), \ldots, A_{k}^{i}\left(x_{k, j}\right)\right] x_{r, j}}{\sum_{i=1}^{n} \operatorname{product}\left[A_{1}^{i}\left(x_{1, j}\right), \cdots, A_{k}^{i}\left(x_{k, j}\right)\right]}
\end{gathered}
$$

where $\alpha_{r}$ is the convergence factor or the step size in the gradient method; subscript index $t$ denotes the iteration sequence, and $x_{r, j}=1.0$ if $\mathrm{r}=0$ in Eq. (2.6b). Usually, the magnitude of $\alpha_{r}$ is chosen based on that of the gradient. Eq. (2.6), together with Eq. (2.6a), would result in summing contributions to the total $p$-coefficients from all data points. Instead, simplification is applied to result in a point-iteration approach, so that in each iteration over the dataset, the $p$-coefficients represent only the contribution from one data point. After simplification, Eq. (2.6) becomes

For $r=0$,

$$
p_{0, t+1}^{i}=p_{0, t}^{i}-2 \alpha_{0}\left(\hat{y}_{j}-y_{j}\right) \times \frac{\operatorname{product}\left[A_{1}^{i}\left(x_{1}\right), \cdots, A_{k}^{i}\left(x_{k, j}\right)\right]}{\sum_{s=1}^{n} \operatorname{product}\left[A_{1}^{s}\left(x_{1, j}\right), \cdots, A_{k}^{s}\left(x_{k, j}\right)\right]}
$$

and for $r=1,2, \ldots, k$,

$$
p_{r, t+1}^{i}=p_{r, t}^{i}-2 \alpha_{r}\left(\hat{y}_{j}-y_{j}\right) \times \frac{\operatorname{product}\left[A_{1}^{i}\left(x_{1}\right), \cdots, A_{k}^{i}\left(x_{k, j}\right)\right] x_{r, j}}{\sum_{s=1}^{n} \operatorname{product}\left[A_{1}^{s}\left(x_{1, j}\right), \cdots, A_{k}^{s}\left(x_{k, j}\right)\right]}
$$

The iteration during the search sequence stops when one of the following three criteria is satisfied (Wang, et al. 1998, 1999):

$$
\begin{gathered}
\text { 1) } \operatorname{Cost}=S S E_{t}<\varepsilon_{1} \\
\text { 2) } \mathrm{RER}=\frac{S S E_{t}-S S E_{t-1}}{S S E_{t}}<\varepsilon_{2} \\
\text { 3) } t=t_{\max }
\end{gathered}
$$

In the above criteria, Cost=SSE $E_{t}$ is the sum of squared errors (SSE) in current iteration to be denoted by "Cost" and RER=(cost_current - cost_previous)/cost_current (i.e. the relative error) for simplicity in descriptions; $\varepsilon_{1}$ and $\varepsilon_{2}$ are the required precision criteria; and $t_{\max }$ is a specified maximum iteration number. The convergence of modeling is achieved only when the first two criteria (Eqs. 2.7 and 2.8) are satisfied. 
Given membership functions and the training data, this parameter identification procedure can be applied to establish a fuzzy-logic model, i.e. determining the p-coefficients in Eq. 2.2. One important reason for the fuzzy logic algorithm, as described above, to work well in nonlinear, robust interpolation is that it employs numerous internal functions to cover the whole ranges of input variables.

\subsection{Model structure identification}

In the fuzzy-logic model, the model structure is indicated by the number of membership functions for each variable. For a fuzzy-logic model with multiple variables, the structure is the combination of the numbers and forms of the membership functions assigned to all input variables. Since the sequence defines the one-to-one relationship between the numbers and the forms for each variable, the structure can be uniquely described by numbers of the membership functions.

The model structure is determined by maximizing the correlation coefficient, Eq. (2.5). A search forward algorithm has been employed for the identification. At each search stage, there may be many fuzzy-logic models with different structure combinations. The search stage numbers are denoted by $N_{s}$. Out of all the possible intermediate fuzzy-logic models at each search stage, for an efficient search, only some structures are developed and evaluated. Two selection criteria, to be given below, are used to choose these structures. With the incremental sequence and the selection criteria, the search forward algorithm is summarized as follows (Wang, et al. 1998):

1. Specify the input variables $x_{r}, r=1,2, \ldots, k$ and the output variable $y$;

2. Assume an initial structure, also called parent structure as $\left(N_{10}, N_{20}, \cdots, N_{r 0}, \cdots, N_{k 0}\right)$;

3. Begin at the search stage number $N_{s}=1$, form all possible structures starting from the parent structure by adding one more membership function a time only to one input variable. Those all possible structures are called child structures as $\left(N_{10}+1, N_{20}, \cdots, N_{r 0}, \cdots, N_{k 0}\right),\left(N_{10}, N_{20}+1, \cdots, N_{r 0}, \cdots, N_{k 0}\right), \cdots$, $\left(N_{10}, N_{20}, \cdots, N_{r 0}, \cdots, N_{k 0}+1\right)$. Perform the identification of internal coefficients in Eq. (2.1) for each child structure and then calculate the $R^{2}$ by using Eq. (2.5);

4. Select the top 5 child structures among all calculated values of $R^{2}$ as new parent structures for next search step $N_{s}=N_{s}+1$;

5. Go back to step 2) starting from the new parent structures and repeat the same procedures in steps 2) and 3) until the best structure is identified;

6. Pick out the maximum value of $R^{2}$ among the child structures in each searching stage as $R_{\max }^{2}$. The structure with the largest $R_{\max }^{2}$ corresponding to all picking values is the optimal structure within a sensible $N_{s}$.

The above process is illustrated in Fig. 3. In the structure identification, parameter identification to determine the p-parameters according to Eq. (2.6) is also needed. But the number of iteration to determine the p-parameters is limited to 2000, so that the best structure is decided on a relative basis. After this last step, Eq. (2.6) is applied iteratively until both the values of $R^{2}$ and RER reach the requirements in the final parameter identification. 


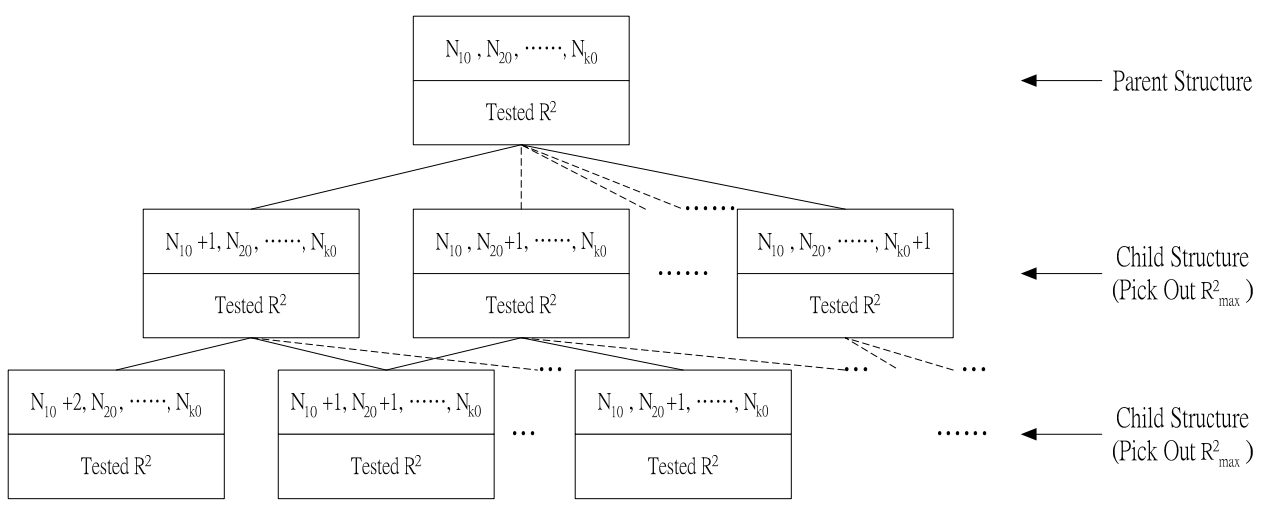

Fig. 3. Identification process for the best structure

\section{Some verification examples}

In application, the more complex the problem is, the more usefulness of the present algorithm would clearly exhibit. A complex problem in identifying the aerodynamic models of a jet transport in severe atmospheric turbulence will be presented in Section 4 . Here, a simpler problem, yet complex enough for a conventional parameter identification method, will be used to show the robustness and reliability of the present algorithm. The idea is to assume the aerodynamic derivatives are known from the wind-tunnel forced oscillation test and the aerodynamic model data are generated from these derivatives. The algorithm is to obtain a numerical model containing the p-coefficients and the aerodynamic derivatives are then estimated for comparison with the test data.

For this purpose, the rolling moment coefficient model will be examined. It is assumed to be a function of

$$
\alpha, \beta, \phi, \mathrm{p}, \mathrm{r}, \mathrm{k}, \dot{\beta}
$$

where $\mathrm{k}=\omega \mathrm{b} / 2 \mathrm{~V}$, the reduced frequency and $\omega$ is the oscillation frequency in the test.

\subsection{Wind-tunnel data}

Define the rolling motion, $\phi(\mathrm{t})$, in wind-tunnel testing being described as follows.

$$
\begin{gathered}
\beta=\alpha_{n} \sin \phi(t) \\
\dot{\beta}=p \sin \alpha_{n} \\
\alpha=\alpha_{n} \cos \phi(t)
\end{gathered}
$$




$$
\phi(t)=-\Delta \phi \cos (k \bar{t})
$$

where $\alpha_{n}$ is the nominal angle of attack used in wind tunnel testing and $\mathrm{p}$ is the roll rate. Since the rolling moment coefficient is also affected by yawing motion, $\psi(t)$, the latter in wind-tunnel testing is assuming to be:

$$
\begin{gathered}
\beta=-\psi \cos \alpha_{n} \\
\dot{\beta}=-\dot{\psi} \cos \alpha_{n}, \\
\dot{\psi}=r, \text { the yaw rate } \\
\alpha=\alpha_{n} \\
\psi(t)=-\Delta \psi \cos (k \bar{t})
\end{gathered}
$$

According to the linear theory, the rolling moment coefficient is calculated from:

$$
C_{l}=C_{l \beta} \beta+C_{l p} \bar{p}+C_{l r} \bar{r}+C_{l \dot{\beta}} \overline{\dot{\beta}}
$$

where the bar over a variable indicate a dimensionless one. For example, $\bar{p}=p b / 2 \mathrm{~V}$, where $\mathrm{V}$ is the airspeed. The verification will be performed at two conditions: one at small oscillation amplitudes, and the other one at large amplitude. These conditions are given in the following.

\subsubsection{Small amplitudes at two reduced frequencies}

\subsubsection{1 $\alpha=5$ deg., $\Delta \phi=5$ deg., $\Delta \psi=5$ deg., $\mathrm{k}=0.12$}

The wind-tunnel data for a test model show: $C_{l \beta}=-0.0688 ; C_{l p}=-0.17 ; C_{l r}=0.06 ; C_{l \dot{\beta}}=-0.04$

Therefore,

$$
\begin{aligned}
& \left(C_{l p}\right)_{o s c}=C_{l p}+C_{l \dot{\beta}} \sin \alpha=-0.1735 \\
& \left(C_{l r}\right)_{o s c}=\mathrm{Clr}-C_{l \dot{\beta}} \cos \alpha=0.0998
\end{aligned}
$$

3.1.1. $\alpha=20$ deg.; $\Delta \phi=5$ deg., $\Delta \psi=5$ deg., $\mathbf{k}=0.08$

The wind-tunnel data show: $C_{l \beta}=-0.2493 ; C_{l p}=-0.10 ; C_{l r}=0.233 ; C_{l \dot{\beta}}=-0.17$

Therefore,

$$
\begin{aligned}
& \left(C_{l p}\right)_{o s c}=C_{l p}+C_{l \dot{\beta}} \sin \alpha=-0.1581 \\
& \left(C_{l r}\right)_{o s c}=C_{l r}-C_{l \dot{\beta}} \cos \alpha=0.3927
\end{aligned}
$$




\subsubsection{Large amplitudes}

3.1.2.1 $\alpha=5$ deg., $\Delta \phi=30$ deg., $\Delta \psi=15$ deg., $k=0.12$

$$
\text { 3.1.2.2 } \alpha=20 \text { deg.; } \Delta \phi=15 \text { deg., } \Delta \psi=15 \text { deg., } \mathrm{k}=0.08
$$

All derivatives are taken to be the same as in the small amplitude case.

\subsection{Modeling results}

Based on Eq. (3.4), two sets of data are generated at $\mathrm{k}=0.12$ and 0.08 , which are then combined into one for modeling. In linear aerodynamic theory, the rolling moment coefficient is known to be independent of the roll angle $(\phi)$. Two models are set up with $\phi=$ 0 or without $\phi$ in Eq. (3.1), and $\phi$ given by Eq. (3.2) to test the robustness of the algorithm. To calculate the response, input data in the form of Eq. (3.4) for a cosine harmonic oscillation are prepared. The output from the model is then Fourier-analyzed to obtain the in-phase and out-of-phase response. The out-of-phase response is the damping component and is what to be presented below. Only the small-amplitude results are presented, because the large-amplitude results are very similar.

\subsection{1 $\alpha=5$ deg., $\Delta \phi=5$ deg., $\Delta \psi=5$ deg., $\mathbf{k}=0.12$}

Assume $\phi(t) \neq 0$ and is given by Eq. (3.2). The modeling results are:

$$
C_{l \beta}=-0.0688 ;\left(C_{l p}\right)_{o s c}=-0.1736 ;\left(C_{l r}\right)_{o s c}=0.0999
$$

On the other hand, if $\phi$ is assumed 0 in the model data, the modeling results are:

$$
C_{l \beta}=-0.0688 ;\left(C_{l p}\right)_{o s c}=-0.1736 ;\left(C_{l r}\right)_{o s c}=0.0999
$$

It is seen that the results are identical at $\alpha=5$ degrees in both cases, and agree with the original wind-tunnel data very well. Same results are obtained if $\phi$ is absent in the model structure.

\subsection{2 $\alpha=20$ deg.; $\Delta \phi=5$ deg., $\Delta \psi=5$ deg., $\mathbf{k}=0.08$}

Again, assume $\phi(t) \neq 0$ and is calculated with Eq. (3.2). The modeling results are:

$$
C_{l \beta}=-0.2493 ;\left(C_{l p}\right)_{o s c}=-0.1581 ;\left(C_{l r}\right)_{o s c}=0.3926
$$

If $\phi=0$ or it is absent in the model data, the modeling results are:

$$
C_{l \beta}=-0.2494 ;\left(C_{l p}\right)_{o s c}=-0.1584 ;\left(C_{l r}\right)_{o s c}=0.3925
$$

The results at $\alpha=20$ degrees are nearly identical, except the last digit and also agree with the original data well.

\subsubsection{Large-amplitude test cases}

The large-amplitude test cases produce similarly accurate results as compared with the wind-tunnel data. Therefore, the results will not be repeated. 


\subsubsection{Concluding remarks}

In the above example the model prediction practically shows the same results as the windtunnel data with or without the extra $\phi(t)$-variable in the model. It illustrates one important concept in the present fuzzy logic aerodynamic modeling that more variables than what are known in the present linear theory may be included in the model without affecting the results of prediction. In the case of nonlinear theory, including more variables in the model allows presently unknown phenomena to be captured at the expense of more computing time.

\subsection{Modeling of wind-tunnel unsteady aerodynamic data}

Verification with other methods is difficult to conduct because of the unavailability of suitable data and published results. However, the present algorithm has been verified with wind-tunnel experimental data. The wind-tunnel data used consist of static, forced oscillation, and some cases with rotary balance data, in numerous sets. These data sets at various angles of attack and reduced frequencies are combined to set up six (6) aerodynamic models. The resulting models can predict aerodynamic hysteresis quite well (Wang, et al. 1998, 1999). To save space, all these correlation results will not be presented, except one pitching moment curve. Fig. 4 presents the comparison of experimental data and modeling prediction. As indicated earlier, the modeling results predict only the mean approximation in the least-square sense and are seen here to re-produce well the hysteresis in the test data. Note that $\mathrm{k}$ is defined as $\omega \bar{c} / \mathrm{V}$ in this case. The arrows indicate the direction of changes in $\mathrm{C}_{\mathrm{m}}$ as $\alpha$ varies in Fig. 4. As will be explained later, if the hysteresis curve is counterclockwise, as shown at low $\alpha^{\prime}$ s, the oscillatory pitch damping derivative is stable (i.e. negative in sign). On the other hand, if it is clockwise, as shown at high $\alpha^{\prime}$, the damping derivative is unstable (i.e. positive in sign).

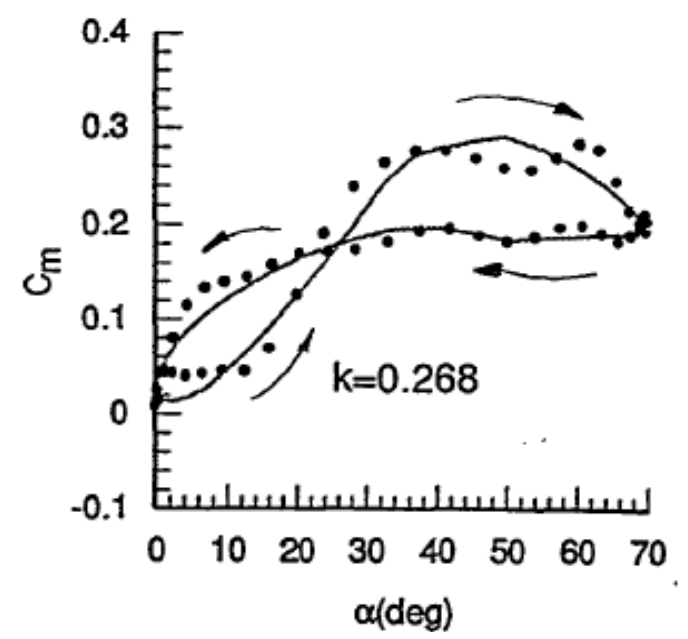

Fig. 4. Comparison of experimental forced oscillation data with modeling results in pitching moment coefficient 


\section{Application to aircraft aerodynamic modeling}

\subsection{Flight data}

The twin-jet transport in the present study encountered clear-air turbulence in cruise flight at the altitude around $10,050 \mathrm{~m}$. As a result, several passengers and cabin crews sustained injuries, because of which this event was classified as an accident. The present study was initiated to examine possible concepts of accident prevention in the future. The dataset used for the modeling are extracted from the FDR during turbulence encounter lasting for 92 seconds.

The main aircraft geometric and inertial characteristics are taken, or estimated, as shown in Table 1:

\begin{tabular}{|l|l|l|l|}
\hline \multicolumn{2}{|l|}{ Geometric data } & \multicolumn{2}{l|}{ Moments of inertia } \\
\hline$W$ (take-off) & $1,431,800 \mathrm{~N}(321900 \mathrm{lb})$ & $I_{x x}$ & $10,710,000 \mathrm{~kg}-\mathrm{m}^{2}\left(7,899,900\right.$ slugs-ft $\left.{ }^{2}\right)$ \\
\hline$S$ & $260 \mathrm{~m}^{2}\left(2798.7 \mathrm{ft}{ }^{2}\right)$ & $I_{y y}$ & $14,883,800 \mathrm{~kg}-\mathrm{m}^{2}\left(10,978,000\right.$ slugs- $\left.\mathrm{ft}^{2}\right)$ \\
\hline $\bar{c}$ & $6.608 \mathrm{~m}(21.68 \mathrm{ft})$ & $I_{z z}$ & $25,283,271 \mathrm{~kg}-\mathrm{m}^{2}\left(18,648,470\right.$ slugs-ft $\left.{ }^{2}\right)$ \\
\hline$b$ & $44.827 \mathrm{~m}(147.08 \mathrm{ft})$ & $I_{x z}$ & $0.0 \mathrm{~kg}-\mathrm{m}^{2}\left(0.0\right.$ slugs-ft $\left.{ }^{2}\right)$ \\
\hline
\end{tabular}

Table 1. The main aircraft geometric and inertial characteristics

The required operational parameters in FDR dataset for generating aerodynamic model data are time $(t)$, CAS, pressure altitude $(h)$, roll attitude $(\phi)$, pitch attitude $(\theta)$, magnetic heading $(\psi)$, longitudinal acceleration $\left(a_{x}\right)$, lateral acceleration $\left(a_{y}\right)$, vertical acceleration $\left(a_{z}\right)$, angle of attack $(\alpha)$, aileron deflection $\left(\delta_{a}\right)$, elevator $\left(\delta_{e}\right)$, rudder $\left(\delta_{r}\right)$, stabilizer $\left(\delta_{s}\right)$, engine EPR, outside air temperature, wind speed, wind direction, and fuel flow rate. Since only the normal acceleration is recorded in $8-\mathrm{Hz}$ resolution (i.e. 8 points per second), all other parameters are interpolated with a monotone cubic spline to the same sampling rate. Based on the principle in flight data analysis, to estimate stability (or sensitivity) derivative with a flight variable, the corresponding flight variable must be sufficiently excited in the flight. This principle can be satisfied by choosing a large time period so that flight variables have sufficient variation during the time period, or by combining different flights if a model to represent a particular aircraft is desired.

\subsection{Compatibility analysis}

Typically, the longitudinal, lateral, and vertical accelerations $\left(a_{x}, a_{y}, a_{z}\right)$ along the $(\mathrm{x}, \mathrm{y}, \mathrm{z})$ body axes of aircraft, angle of attack $\alpha$, and the Euler angles $(\phi, \theta$, and $\psi)$, as well as all control deflections are available and recorded in the FDR of all transport aircraft. Since the recorded flight data may contain errors (or called biases), compatibility analysis is performed to remove them by satisfying the following kinematic equations:

$$
\begin{gathered}
\dot{\phi}=p+q \sin \phi \tan \theta+r \cos \phi \tan \theta \\
\dot{\theta}=q \cos \phi-r \sin \varphi \\
\dot{\psi}=(q \sin \phi+r \cos \phi) \sec \theta
\end{gathered}
$$




$$
\begin{gathered}
\dot{V}=\left(a_{x}-g \sin \theta\right) \cos \alpha \cos \beta+\left(a_{y}+g \sin \phi \cos \theta\right) \sin \beta+\left(a_{z}+g \cos \phi \cos \theta\right) \sin \alpha \cos \beta \\
\dot{\alpha}=\left[\left(a_{z}+g \cos \theta \cos \phi\right) \cos \alpha-\left(a_{x}-g \sin \theta\right) \sin \alpha\right] /(V \cos \beta)+q-\tan \beta(p \cos \alpha+r \sin \alpha) \\
\dot{\beta}=\cos \beta\left(a_{y}+g \cos \theta \sin \phi\right) / V+p \sin \alpha-r \cos \alpha \\
-\sin \beta\left[\left(a_{z}+g \cos \theta \cos \phi\right) \sin \alpha-\left(a_{x}-g \sin \theta\right) \cos \alpha\right] / V
\end{gathered}
$$

where $\mathrm{g}$ is acceleration due to gravity, $V$ is flight speed, $\beta$ is sideslip angle, $p$ is roll rate, $q$ is pitch rate, and $r$ is yaw rate in Eqs. (4.1) (4.6). Let the biases be denoted by $b_{a_{x}}, b_{a_{y}}, b_{a_{z}}, b_{p}, b_{q}, b_{r}, b_{V}, b_{\alpha}, b_{\beta}, b_{\theta}, b_{\varphi}, b_{\psi}$, respectively for $a_{x}, a_{y}, a_{z}$, etc. These biases are estimated by minimizing the squared sum of the differences between the two sides of the above equations. These equations in vector form can be written as:

$$
\dot{\bar{z}}=\vec{f}(x)=\vec{f}\left(x_{m}-\Delta x\right)
$$

where

$$
\begin{gathered}
\vec{z}=(V, \alpha, \beta, \theta, \phi, \psi)^{T} \\
\vec{x}_{m}=\left(a_{x}, a_{y}, a_{z}, p, q, r, V, \alpha, \beta, \theta, \phi, \psi\right)^{T} \\
\Delta \vec{x}=\left(b_{a_{x}}, b_{a_{y}}, b_{a_{z}}, b_{p}, b_{q}, b_{r}, b_{V}, b_{\alpha}, b_{\beta}, b_{\theta}, b_{\phi}, b_{\varphi}\right)^{T}
\end{gathered}
$$

where the subscript " $m$ " indicates the measured or recorded values. The cost function is defined as:

$$
J=\frac{1}{2}(\dot{\bar{z}}-\vec{f})^{T} Q(\dot{\bar{z}}-\vec{f})
$$

where $Q$ is a weighting diagonal matrix with elements being 1.0 except the one for the slowly varying flight speed being 10.0 and $\dot{\bar{z}}$ is calculated with a central difference scheme with $\vec{z}_{m}$, which is the measured value of $\vec{z}$. The steepest descent optimization method is adopted to minimize the cost function. As a result of the analysis, variables not present in the FDR, such as $\beta, p, q$ and $r$, are also estimated.

The force and moment coefficients are obtained from the following flight dynamic equations (Roskam 2003) about the airplane body axes:

$$
\begin{gathered}
m a_{x}=C_{x} \bar{q} S+T_{x} \\
m a_{y}=C_{y} \bar{q} S+T_{y} \\
m a_{z}=C_{z} \bar{q} S+T_{z} \\
C_{l} \bar{q} S b=I_{x x} \dot{p}-I_{x z}(\dot{r}+p q)-\left(I_{y y}-I_{z z}\right) q r
\end{gathered}
$$




$$
\begin{gathered}
\mathrm{C}_{m} \bar{q} S \bar{c}=I_{y y} \dot{q}-I_{x z}\left(r^{2}-p^{2}\right)-\left(I_{z z}-I_{x x}\right) r p-T_{m} \\
\mathrm{C}_{n} \bar{q} S b=I_{z z} \dot{r}-I_{x z}(\dot{p}-q r)-\left(I_{x x}-I_{y y}\right) p q
\end{gathered}
$$

where $m$ is the aircraft mass; $\bar{q}$ the dynamic pressure; $S$ the wing reference area; $C_{x}, C_{z}$, and $C_{m}$ the longitudinal aerodynamic force and moment coefficients; $C_{y}, C_{l}$, and $C_{n}$ the lateraldirectional aerodynamic force and moment coefficients; $I_{x x}, I_{y y}$, and $I_{z z}$ the moments of inertia about $x-, y$-, and $z$-axes, respectively; $I_{x y}, I_{x z}$, and $I_{y z}$ the products of inertia; and $T_{x}, T_{y}$, $T_{z}$, and $T_{m}$ the thrust terms about $x-, y$-, $z$-axes, and in equation of pitching moment, respectively in Eqs. (4.12) (4.17).

The above equations are used to determine all aerodynamic coefficients based on accelerometer readings $\left(a_{x}, a_{y}\right.$, and $\left.a_{z}\right)$, Euler angles $(\phi, \theta$, and $\psi)$, angular rates $(p, q$ and $r)$, and thrusts $\left(T_{x}, T_{y}, T_{z}\right.$, and $\left.T_{m}\right)$. The angular rates are estimated through compatibility analysis. Since thrust was not measured during flight for most flight vehicles, those values and the effects on the forces and pitching moments in equations of (4.12), (4.13), (4.14), and (4.16) should be predicted by a thrust model (see Section 4.4).

\subsection{Equivalent harmonic motion}

The reduced frequency is a parameter to indicate the degree of unsteadiness in unsteady aerodynamics and is estimated in this paper by fitting the local trajectory with a harmonic motion. In the static case, the reduced frequency is 0 . Large values of the reduced frequency imply the importance of unsteady aerodynamic effect. For longitudinal aerodynamics, the equivalent harmonic motion is the one based on the angle-of-attack variation following the classical unsteady aerodynamic theory of Theodorsen (Theodorsen 1935). For lateraldirectional aerodynamics, it is based on the time variation of roll angle (Wang, et al. 1998).

For the longitudinal motion, the time history of the angle of attack $(\alpha)$ and time rate of angle of attack $(\mathrm{d} \alpha / \mathrm{dt}$, or $\dot{\alpha})$ is fitted with one of a harmonic motion at any instant as follows (Wang, et al. 1998):

$$
\begin{gathered}
\alpha(t)=\bar{\alpha}+\alpha \cos (\omega t+\bar{\phi}) \\
\dot{\alpha}(t)=-a \omega \sin (\omega t+\bar{\phi})
\end{gathered}
$$

where those terms on the left hand side of Eqs. (4.18) and (4.19) are given and the unknowns are the local mean angle of attack $(\bar{\alpha})$, the local amplitude of the harmonic motion $(a)$, the phase lag $(\bar{\varphi})$, and the angular frequency $(\omega)$. These unknowns are calculated through an optimization method by minimizing the following cost function (least squares)

$$
J=\sum_{i=1}^{n}\left[\alpha_{i}-\left(\bar{\alpha}+a \cos \left(\omega t_{i}+\bar{\phi}\right)\right)\right]^{2}+\left[\dot{\alpha}_{i}-\left(\bar{\alpha}+a \omega \sin \left(\omega t_{i}+\bar{\phi}\right)\right)\right]^{2}
$$

In Eq. (4.20), where $\alpha_{i}$ is the measured value at point $i$ and $n$ is the number of the data points used in the optimization. For the case in the present study, $n=20$ is found to be the best 
choice by correlating with a cosine wave with a constant frequency. The 20 points preceding and including the current time are employed in Eq. (4.20). The least-square method is found to converge well and gives reasonably accurate results. The lateral-directional equivalent reduced frequency is computed in the same manner.

The local equivalent reduced frequency in the longitudinal motion is defined as,

$$
k_{1}=\frac{\omega \bar{c}}{V}
$$

where $\bar{c}$ is the mean chord length of wing airfoil section. The lateral-directional equivalent reduced frequency is defined as

$$
k_{2}=\frac{\omega b}{2 V}
$$

where $b$ is the wing span.

\subsection{Fuzzy-Logic thrust model}

As shown before, the thrust terms appear in the force equations and the pitching moment equation (Eqs. 4.12 4.14 and 4.16; but in the current application, $\mathrm{T}_{\mathrm{y}}=\mathrm{T}_{\mathrm{z}}=0$.). Since the values of thrust for aircraft in flight cannot be directly measured in the current state of the art, they are not recorded in the FDR. The manufacturers of engines agreed that using such parameters as the Mach number, airspeed, flight altitude, temperature, the rpm of the pressure compressors and engine pressure ratios is adequate to estimate the engine thrust. A realistic thrust model is quite complex and cannot be represented by any simple equation. Since such thrust model is not available for the present study, a realistic one tied to the recorded engine performance parameters is developed with the fuzzy-logic algorithm.

For a commercial aircraft, most likely only the axial force and the pitching moment are affected by thrust. This assumption will be made in this Chapter. Theoretically, clear-air turbulence (i.e. random change in $\mathrm{u}, \mathrm{w}$ (or $\alpha$ ) and $\mathrm{v}($ or $\beta$ )) affect the engine performance through its effects on static and dynamic distortions at the engine face. However, its effects are not known and cannot be estimated, and therefore ignored in the present application.

For the present purpose, data from the flight manual for the fuel flow rates $\left(\dot{m}_{f}\right)$ at various altitudes $(h)$, weights $(W)$, Mach numbers $(M)$, calibrated airspeed (CAS), engine pressure ratios (EPR), in cruise flight are utilized. Note that the drag polar for a given aircraft is generally not known to most researchers. To estimate it and hence the thrust magnitude in cruise, the assumption of a design lift-to-drag ratio $(L / D)$ of 17.5 is made. This value of liftto-drag in cruise is assumed based on the past design experience for twin-jet transports. In the flight manual, various weights, altitudes, Mach numbers, CAS, EPR, and fuel flow rates in cruise are tabulated. The lift coefficient can be calculated at each flight condition immediately. As a result, the drag coefficient can be estimated from the assumption of liftto-drag ratio. Therefore, the design thrust in cruise at various Mach numbers can be estimated. For the Pratt \& Whitney turbofan engines, thrust $(T)$ is defined by EPR, so that the thrust model is set up as: 


$$
T=f\left(h, W, M, \text { CAS, EPR, } \dot{m}_{f}\right)
$$

For GE or CFM turbofan engines, the rpm of the low-pressure compressor $\left(N_{1}\right)$ is used to set the level of thrust, so that the thrust model is set up as:

$$
T=f\left(h, W, M, \text { CAS, } N_{1}, \dot{m}_{f}\right)
$$

In the present study, the $P \& W$ turbofan engines powering the twin-jet transport under study will be illustrated. The actual thrust in operation is obtained by using the recorded variables in the FDR, in particular the fuel flow rates.

The following climb equation (Lan \& Roskam 2008) is to be satisfied in the least square sense over a 5-second internal:

$$
\frac{W}{g} \frac{d V}{d t}=T-D-W \sin \gamma
$$

and

$$
\frac{D}{W}=\frac{D}{L} \cos \gamma
$$

All these equations are still valid in descent with negative climb angles $(\gamma)$. The above equations are further employed for parameter identification in the process of modeling.

Once the thrust model is generated as a function of $h, W, M$, CAS, EPR, and $\dot{m}_{f}$ with the flight conditions of climbing, cruise, and descent, one can estimate the thrust magnitude by inserting these flight variables from the FDR into the model.

\subsection{Fuzzy-Logic unsteady aerodynamic models}

Modeling means to establish the numerical relationship among certain variables of interest. In the fuzzy-logic model, more complete necessary influencing flight variables can be included to capture all possible effects on aircraft response to atmospheric disturbances. For longitudinal aerodynamics, the models are assumed to be of the form:

$$
C_{x}, C_{z}, C_{m}=f\left(\alpha, \dot{\alpha}, q, k_{1}, \beta, \delta_{e}, M, p, \delta_{s}, \bar{q}\right)
$$

where the left hand side represents the coefficients of axial force $\left(C_{x}\right)$, normal force $\left(C_{z}\right)$, and pitching moment $\left(C_{m}\right)$, respectively. All variables on the right hand side of Eq. (4.27) have been defined in the previous section. It should be noted that the stabilizer angle $\left(\delta_{\mathrm{s}}\right)$ is included here, because it varies, though slowly, in flight to provide pitch trim (i.e. reducing the total static pitching moment to 0.0 ). The roll rate is included here because it is known that an aircraft under high aerodynamic loads at transonic speeds may have its longitudinal stability derivatives affected when additional disturbance due to roll rate is imposed.

For the lateral-directional aerodynamics, 


$$
C_{y}, C_{l}, C_{n}=f\left(\alpha, \beta, \phi, p, r, k_{2}, \delta_{a}, \delta_{r}, M, \dot{\alpha}, \dot{\beta}\right)
$$

where the left hand side represents the coefficients of side force $\left(C_{y}\right)$, rolling moment $\left(C_{l}\right)$ and yawing moment $\left(C_{n}\right)$, respectively.

\subsection{Numerical results and discussions}

In the present study, the accuracy of the established unsteady aerodynamic models with six aerodynamic coefficients by using FLM technique is estimated by the sum of squared errors (SSE) and the square of multiple correlation coefficients $\left(R^{2}\right)$. Fig. 5 presents the aerodynamic coefficients of normal force $C_{z}$, pitching moment $C_{m}$, rolling moment $C_{l}$, and yawing moment $C_{n}$ predicted by the unsteady aerodynamic models. The predicted data by the final refined models have good agreement with the flight data. The $C_{m}$-data scattering is most likely caused by turbulence-induced buffeting on the structure, in particular on the horizontal tail. Once the aerodynamic models are set up, one can calculate all necessary derivatives to analyze the stability.

The fuzzy-logic aerodynamic models are capable of generating the continuous derivatives for the static and dynamic stability study of a twin-jet transport in turbulence response. Firstly, how the fuzzy-logic prediction is achieved will be illustrated with one numerical example in the $C_{z}$ calculation. At first, the range for each variable is defined to be larger than what actually occurred in the present set of $C_{z}$-data as follows:

$[\alpha]=[-13,12],[\dot{\alpha}]=[54,50],[q]=[-20,10],\left[k_{1}\right]=[0,0.6],[\beta]=[-7,3],\left[\delta_{e}\right]=[-10,6],[M]=[0,1.6],[p]=[-$ $24,38],\left[\delta_{s}\right]=[-3,3],[\bar{q}]=[4.964,21.746]$

For the first cell $(1,1,1,1,1,1,1,1,1,1)$, the coefficients in Eq. (2.1) after model training are found to be:

$p_{k}^{1}=(2.61755,1.26662,1.42338,2.07962,-0.44241,2.78017,1.78150,1.30818,1.82872,1.67592$, 1.13787).

Assume that in the following flight conditions $C_{z}$ is to be predicted:

$\alpha=6.91015$ deg.; $\dot{\alpha}=2.95510 \mathrm{deg} / \mathrm{sec} ; q=1.16609 \mathrm{deg} / \mathrm{sec} ; k_{1}=0.01965 ; \beta=-1.55252 ; \delta_{e}=$ $0.68120 \mathrm{deg} ; M=0.77279 ; p=-2.62359 \mathrm{deg} / \mathrm{sec} ; \delta_{\mathrm{s}}=-0.13930 \mathrm{deg}, \bar{q}=11.0545 \mathrm{kpa}$

These values of variables are converted to [0, 1]. For example,

$x_{\alpha}=[6.91015-(-13)] /[12-(-13)]=0.79641$

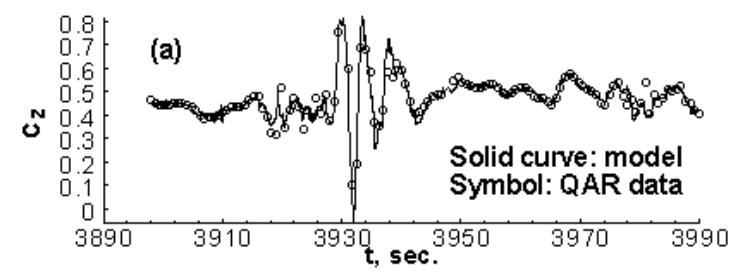



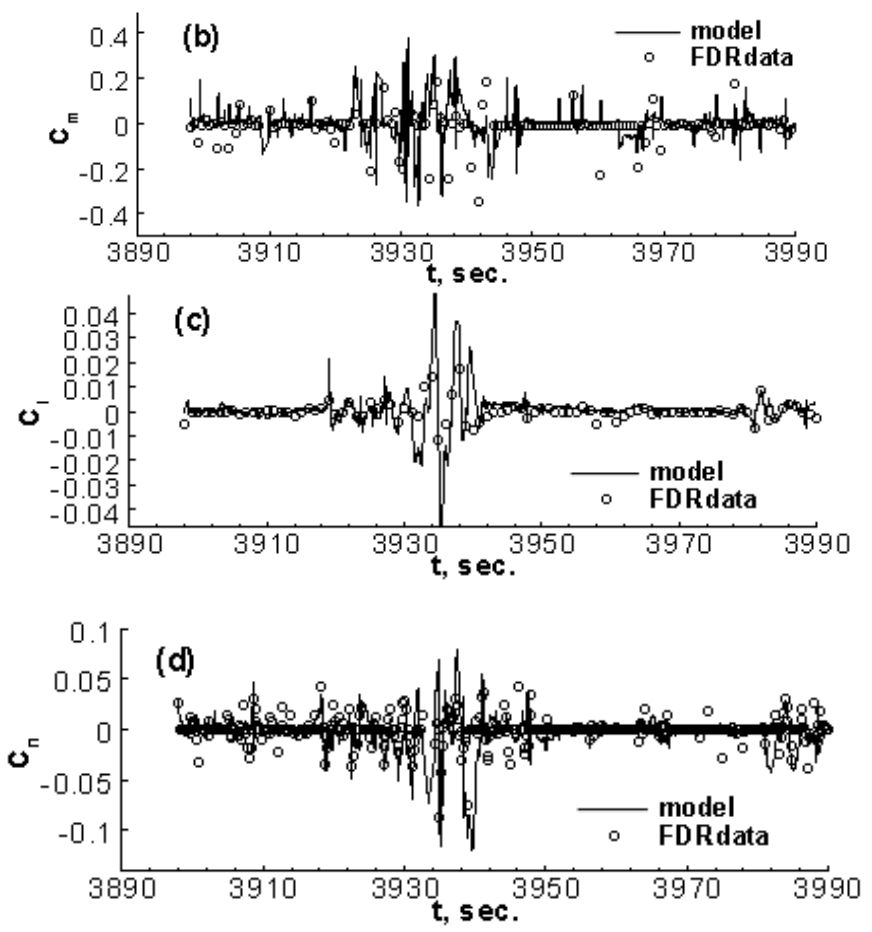

Fig. 5. Predicted aerodynamic coefficients in normal force and moments for a twin-jet transport encountering severe atmospheric turbulence at cruise altitudes around 10,050 m

Other variable values are converted in the same way. It follows that the cell internal function becomes

$P^{1}=2.61755+(1.26662)^{*}(0.79641)+(1.42338)^{*}(0.54764)+(2.07962) *(0.70554)-$

$(0.44241) *(0.03275)+(2.78017) *(0.54475)+(1.7815) *(0.66758)+(1.30818) *(0.48299)+(1.82872) *(0.3$ $4478+(1.67592) *(0.47678)+(1.13787) *(0.3730)=11.04817$

The membership grades for the first cell are exactly equal to $x_{r}$, being $0.79641,0.54764$, etc. Their product can be calculated to be $1.08536 \mathrm{E}-004$. Therefore, the contribution of the first cell to the total output is

\section{$11.04817^{*} 1.08536 \mathrm{E}-004=1.19912 \mathrm{E}-003$}

The total output from all cells can be calculated to be 5.9962; while the denominator in Eq. (2.3) is calculated to be 7.46459. Therefore, the final prediction is 0.8033 . Comparing with data of 0.81038 , this prediction has an error of $-0.88 \%$.

To examine the stability characteristics, it is imperative to understand the flight environment in detail. The corresponding flight data are presented in Fig. 6. Note that $a_{z}$ is the same as $a_{n}$, the normal acceleration. The variation of normal acceleration is presented in Fig. 6(a), showing the highest $a_{n}$ being $1.75 \mathrm{~g}$ around $\mathrm{t}=3930 \mathrm{sec}$ and the lowest being $0.02 \mathrm{~g}$ around $\mathrm{t}=3932 \mathrm{sec}$. Fig. $6(\mathrm{~b})$ shows that $\alpha$ is approximately in phase with $a_{n}$. When $a_{n}$ is the 
highest (around $t=3930 \mathrm{sec}$ ), the aircraft rapidly plunging downward with the altitude $(h)$ reaching the lowest as shown in Fig. 6(c); and $\alpha$ is highest about 6.5 deg. in Fig. 6(b). At the same time, $M$ is around 0.77 in Fig. 6(d). Since $\alpha$ reaches a value about 6.5 deg in transonic flight, compressibility effect is important. It should be noted that the turbulent vertical wind field was not measured or estimated in the FDR; but is included in the total $\alpha$.
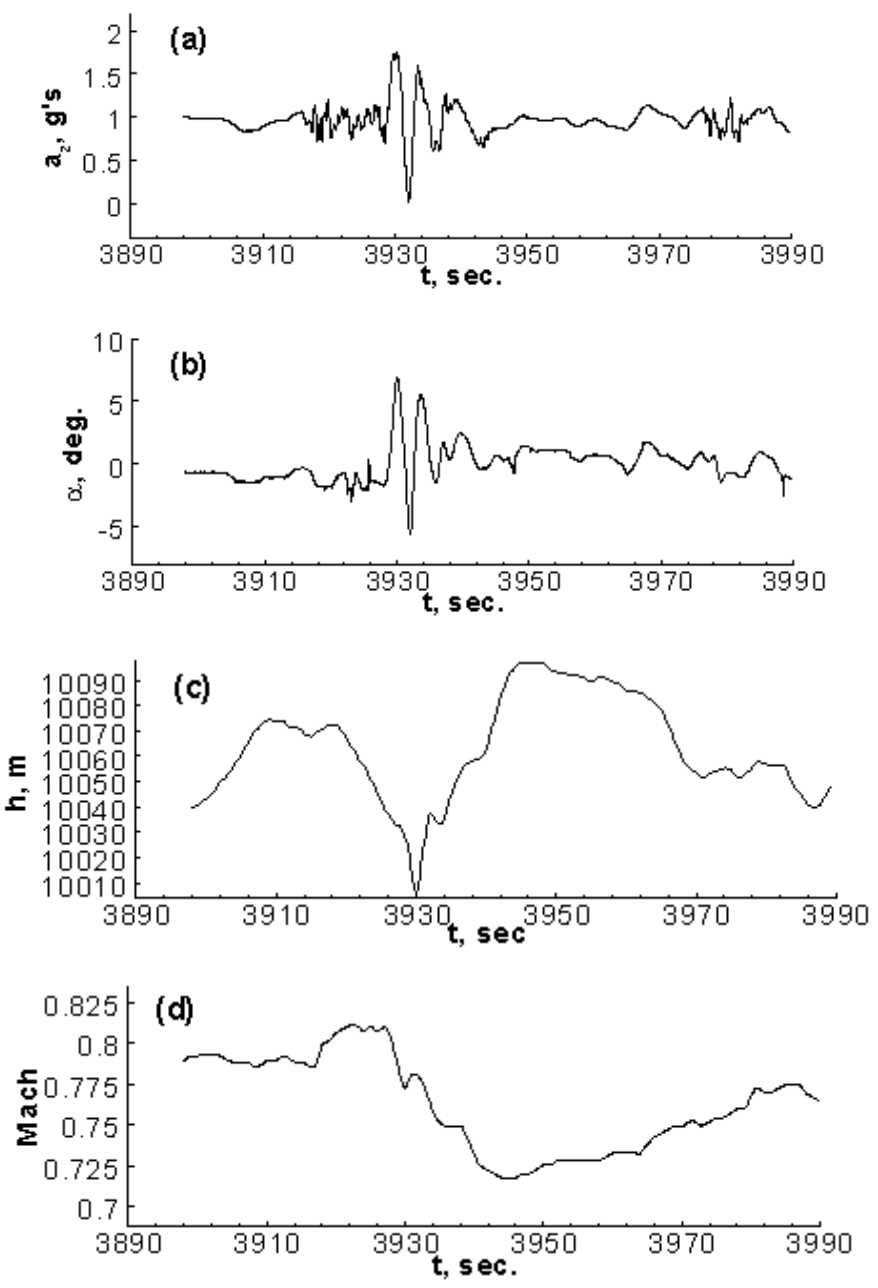

Fig. 6. The time history of flight variables for a twin-jet transport in severe atmospheric turbulence at the altitude around 10,050 $\mathrm{m}$ in transonic flight

The aerodynamic derivatives extracted from the unsteady aerodynamic models can be calculated with a central difference scheme. The longitudinal stability derivative $\left(C_{m \alpha}\right)$ is extracted from the model of $C_{m}$. It is evaluated with the central difference approach as follows: 


$$
C_{m \alpha}=\left[C_{m}(\alpha+\Delta \alpha,--)-C_{m}(\alpha-\Delta \alpha,--)\right] / 2 \Delta \alpha
$$

where $\Delta \alpha=0.5$ degree represents that $\alpha$ is perturbed by 0.5 degree while keeping all other variables unchanged.

The roll damping $\left(C_{l p}\right)$ is extracted from the models of $C_{l}$ with the central difference approach as follows:

$$
C_{l p}=\left[C_{l}(---, p+\Delta p,--)-C_{l}(---, p-\Delta p,--)\right] / 2 \Delta p
$$

where $\Delta p$ is in deg/sec. Similarly, all other aerodynamic derivatives are calculated by using the same method.

\subsubsection{Effects of membership shape functions}

Before presenting the full aerodynamic characteristics, it is desirable to examine the effect of membership shape functions. The normal force coefficient, $C_{z}=C_{N}$, and its derivatives in $\alpha$ and $\mathrm{d} \alpha / \mathrm{dt}$ play an important role in the plunging motion. Therefore, only these two derivatives are compared in Fig. 7. $R^{2}$ for the triangular and parabolic shapes are 0.9787 and 0.9786, respectively. Although the values of $R^{2}$ are close to each other, details in the derivatives do differ, in particular in $C_{N \dot{\alpha}}$ in plunging motion, probably because in the neighborhood of the peak values of the shape functions, the difference in the membership grades tends to be small. As a result, the effect of parabolic shape functions would smooth out the variation.
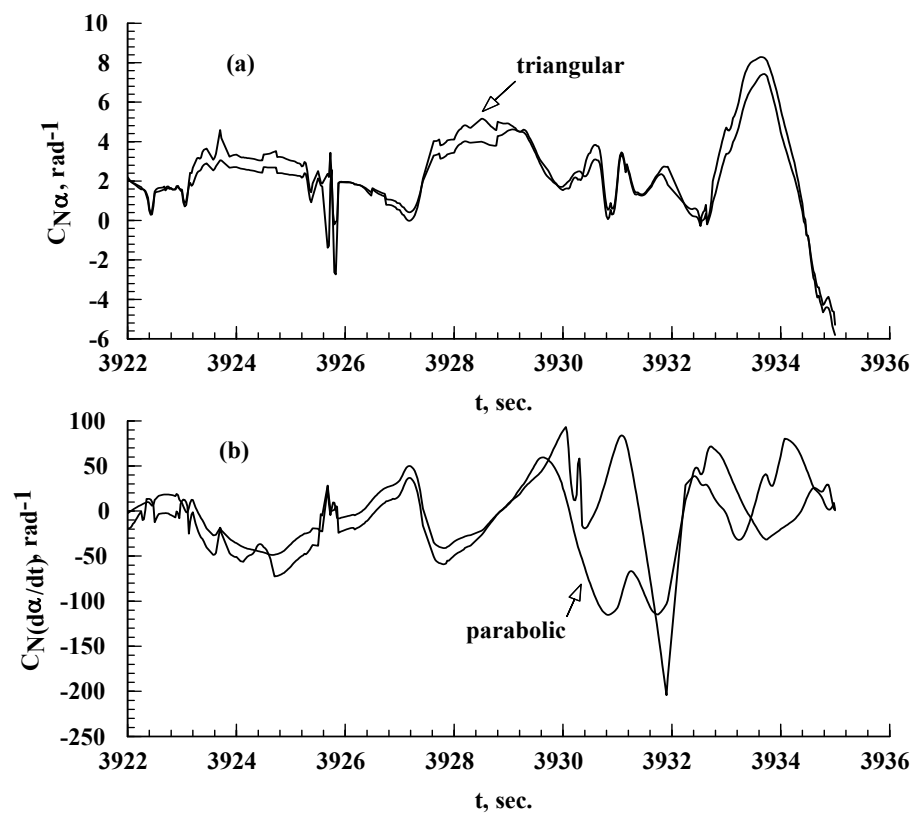

Fig. 7. Effects of membership shape functions on estimated $\alpha$ - and $d \alpha /$ dt- derivatives of $C_{N}$ of a transport aircraft in atmospheric turbulence with plunging motion 
From a physical point of view, it is expected that in plunging motion the $C_{N \dot{\alpha}}$-derivative, which basically represents the virtual mass effect in unsteady aerodynamics (Sheu \& Lan, 2011), should vary sharply. Note that the dynamic derivative, $C_{N \dot{\alpha}}$, is dimensionless (see below). In addition, with parabolic shape functions, modeling tends to take longer to converge. Therefore, in the following all derivatives are based on the model with the triangular membership shape functions.

\subsubsection{Stability derivatives for the whole time period}

The time period between $3927.5 \mathrm{sec}$ and $3932.5 \mathrm{sec}$ is emphasized in evaluating the stability characteristics, because of the plunging motion that affects the flight safety the most. All derivatives are converted to dimensionless ones in accordance with internationally known definition. For example, $\mathrm{C}_{l p}$ is defined as $\partial \mathrm{C}_{l} / \partial(\mathrm{pb} / 2 \mathrm{~V})$ and $\mathrm{C}_{m q}$ as $\partial \mathrm{C}_{m} / \partial(\mathrm{q} \bar{c} / 2 \mathrm{~V})$, where $\bar{c}$ is the mean chord length. Therefore, the units of all aerodynamic derivatives are in $\mathrm{rad}^{-1}$. The main longitudinal and lateral-directional stability derivatives along the flight path are presented in Fig. 8. It should be noted that these derivatives are evaluated at the instantaneous conditions, instead of about the trim conditions as have been traditionally done. From the point of view in static stability, initially, the configuration has longitudinal stability $\left(C_{z \alpha}>0\right.$ and $\left.C_{m \alpha}<0\right)$ as shown in Fig. $8(a)$, stable longitudinal damping $\left(C_{m q}<0\right)$ in Fig. $8\left(\right.$ b) , lateral stability $\left(C_{l \beta}<0\right)$ and directional stability $\left(C_{n \beta}>0\right)$ in Fig. $8(\mathrm{c})$, small roll damping $\left(C_{l p}<0\right)$ and insufficient directional damping $\left(C_{n r}\right.$ small or positive $)$ in Fig. 8(d). During the plunging motion, in the period between $\mathrm{t}=3928.5 \mathrm{sec}$. and $\mathrm{t}=3930.5 \mathrm{sec}, C_{m \alpha}>0$ and $C_{l \beta}>0$, so that the static stability becomes unstable. The aerodynamic instability is most likely caused by the motion that produces a time-dependent pressure distribution on the aircraft surface involving compressibility effects.
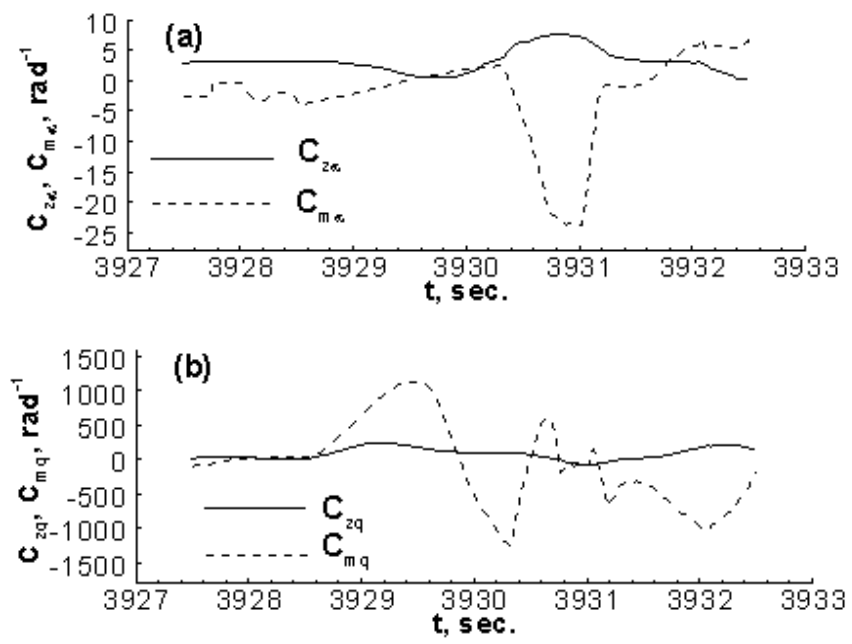

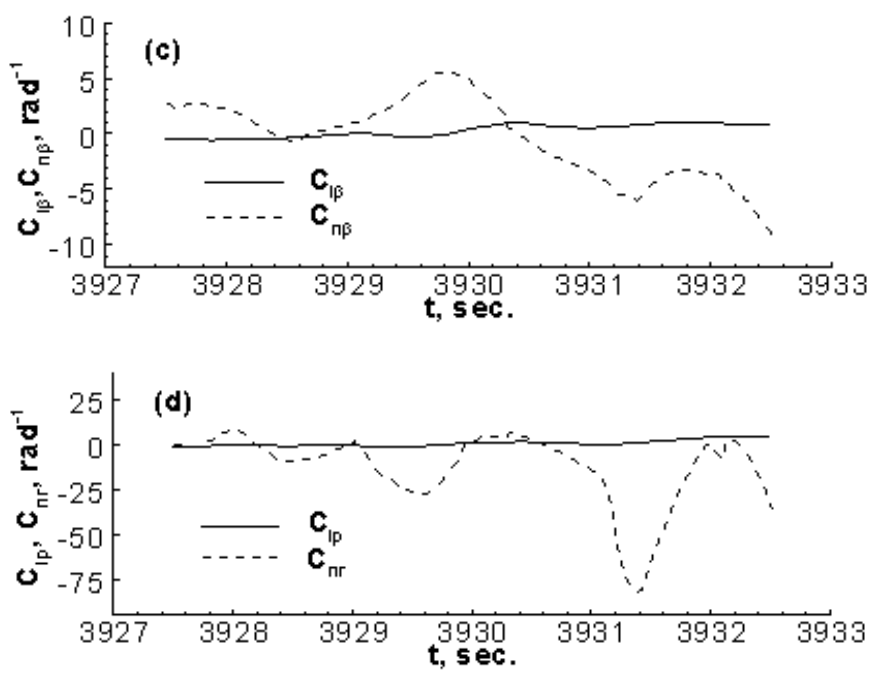

Fig. 8. The time history of main longitudinal and lateral-directional of the static stability derivatives along the flight path

Fig. 9 presents the time history of main longitudinal and lateral-directional oscillatory derivatives along the flight path involving the $\dot{\alpha}$ and $\dot{\beta}$-derivatives. Note that in Fig. 9(a), the oscillatory derivatives are defined as:

$$
\begin{gathered}
\left(C_{m q}\right)_{o s c}=C_{m q}+C_{m \dot{\alpha}} \\
\left(C_{z q}\right)_{o s c}=C_{z q}+C_{z \dot{\alpha}}
\end{gathered}
$$

In Fig. 9(c), the oscillatory derivatives are defined as

$$
\begin{gathered}
\left(C_{l p}\right)_{o s c}=C_{l p}+C_{l \dot{\beta}} \sin \alpha \\
\left(C_{n r}\right)_{o s c}=C_{n r}-C_{n \dot{\beta}} \cos \alpha
\end{gathered}
$$

During the plunging motion, the values have some differences between oscillatory and damping derivatives in Fig. 9(a) $\left(\mathrm{C}_{m q}\right.$ and $\left.\left(\mathrm{C}_{m q}\right)_{\text {osc }}\right)$ and $9(\mathrm{c})\left(\mathrm{C}_{n r}\right.$ and $\left.\left(\mathrm{C}_{n r}\right)_{\text {osc }}\right)$ due to the effects of the dynamic derivatives (i.e. $\dot{\alpha}$ and $\dot{\beta}$-derivatives). The effects of $\dot{\alpha}$-derivative on $\left(C_{z q}\right)_{o s c}$, and $\dot{\beta}$-derivative on $\left(C_{l p}\right)_{o s c}$ are small. However, the effect of $\dot{\alpha}$-derivative on $\left(C_{m q}\right)_{o s c}$ is to improve the stability in pitch after $\mathrm{t}=3929.5 \mathrm{sec}$; while the effects of $\dot{\beta}$-derivative is to cause the directional characteristics more unstable (i.e. $\left(C_{n r}\right)_{o s c}$ more positive). These results indicate that the turbulent crosswind has the effects on directional stability and damping. Although the dynamic derivatives tend to be small for the present configuration, these are much helpful to understand the unknown factors of instability characteristics. To be stable, $\left(C_{z q}\right)_{o s c}<0,\left(C_{m q}\right)_{o s c}<0,\left(C_{l p}\right)_{o s c}<0$, and $\left(C_{n r}\right)_{o s c}<0$. Physically, if it is unstable, the motion will be divergent in oscillatory motions. 

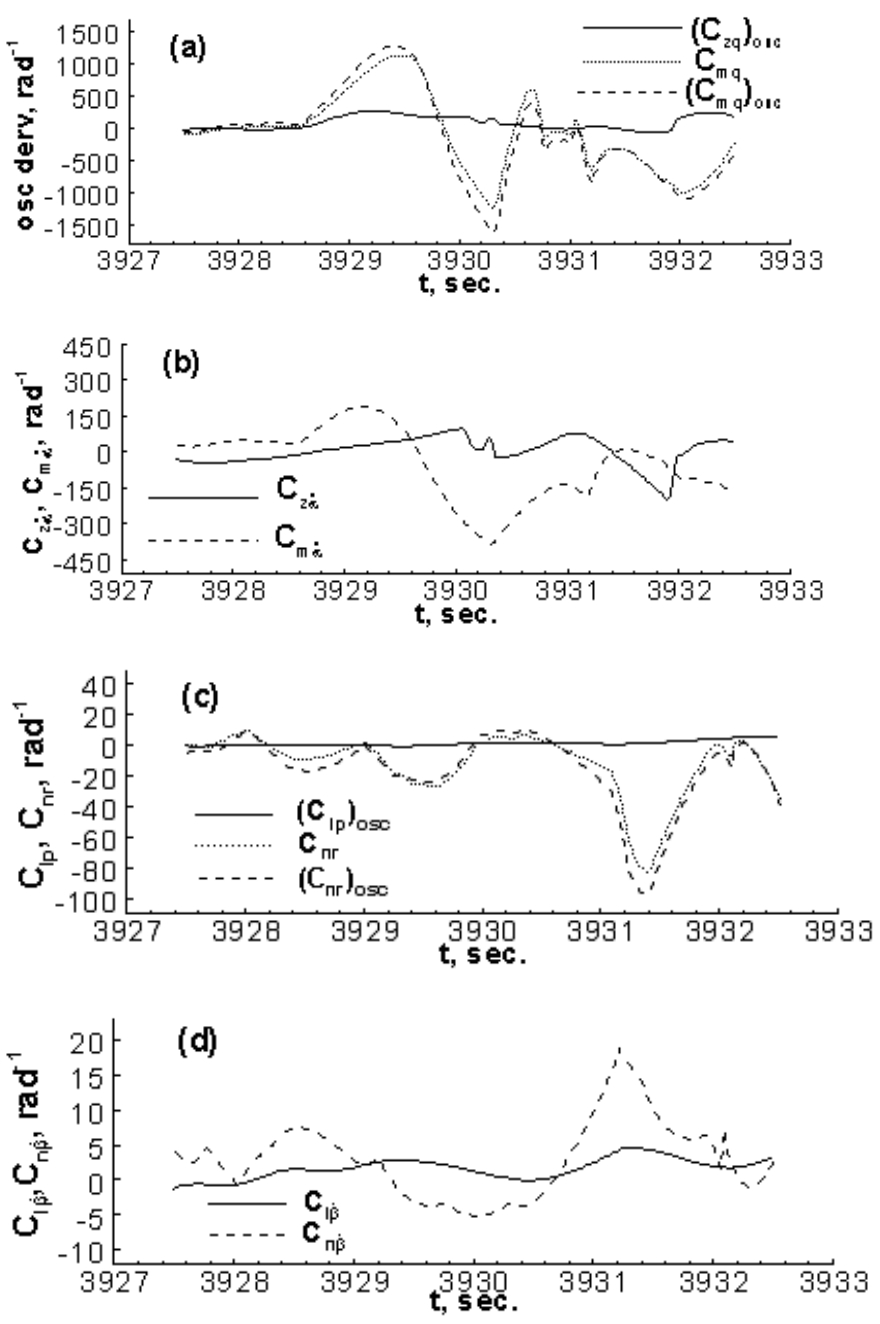

Fig. 9. The time history of main longitudinal and lateral-directional oscillatory derivatives along the flight path

All derivatives in Eqs. (4.31) (4.34) are estimated individually with the aerodynamic models and added afterwards to retain the nonlinearity. In wind-tunnel testing, these derivatives are not separately measured; instead they are determined in combination. As an example, assuming that it is desired to extract the response in $C_{N}$ and $C_{m}$ at average conditions given by $\mathrm{k}_{1}=0.02, \beta=-1.5, \delta_{\mathrm{e}}=0.0, \mathrm{M}=0.78, \mathrm{p}=-3.0 \mathrm{deg} / \mathrm{sec}, \delta_{\mathrm{s}}=-0.5, \mathrm{~V}=817$ $\mathrm{ft} . / \mathrm{sec} ., \bar{q}=234 \mathrm{psf}$ (see Eq. 4.27). The corresponding flight condition is approximately the one during the plunging motion. The angle of attack is assumed to vary harmonically (e.g. a cosine function) with a reduced frequency equal to $\mathrm{k}_{1}$. From the fuzzy-logic models, the response can be determined to be as shown in Fig. 10. The arrows represent the directions of 
change in $\mathrm{a}$. According to a linear theory for $\mathrm{C}_{\mathrm{N}}$ and $\mathrm{C}_{\mathrm{m}}$ as functions of $\mathrm{a}, \dot{\alpha}, \mathrm{q}$ and $\dot{q}$ (see Eq. 3.4 for the example of an expression based on a linear theory), the following in-phase and out-of-phase integrals are given by: using $\mathrm{C}_{\mathrm{N}}$ as an example,

$$
\begin{gathered}
\text { In-phase: } \int_{0}^{2 \pi} C_{N} \alpha d \theta \\
\text { Out-of-phase: } \int_{0}^{2 \pi} C_{N}(d \alpha / d \theta) d \theta
\end{gathered}
$$

After integration, Eq. (4.36) should produce Eq. (4.32) with $C_{z}$ interpreted as $C_{N}$. In addition, as shown in Fig. 10(a), the direction of the hysteretic curve is clockwise, and Eq. (4.36) should produce a positive value based on the linear theory. The sign of the integral (4.35), is represented by the slope of the hysteretic curve. Similarly, for the pitching moment, Fig. 10 (b), the direction of the hysteretic curve is counterclockwise and hence the out-of-phase integral should produce a negative value according to the linear theory (i.e. stable damping). The example illustrates the fact that the present fuzzy-logic models can produce results to simulate the forced-oscillation testing. Typically, the linear results are used in design; while the nonlinear results can be used in performance and simulation.
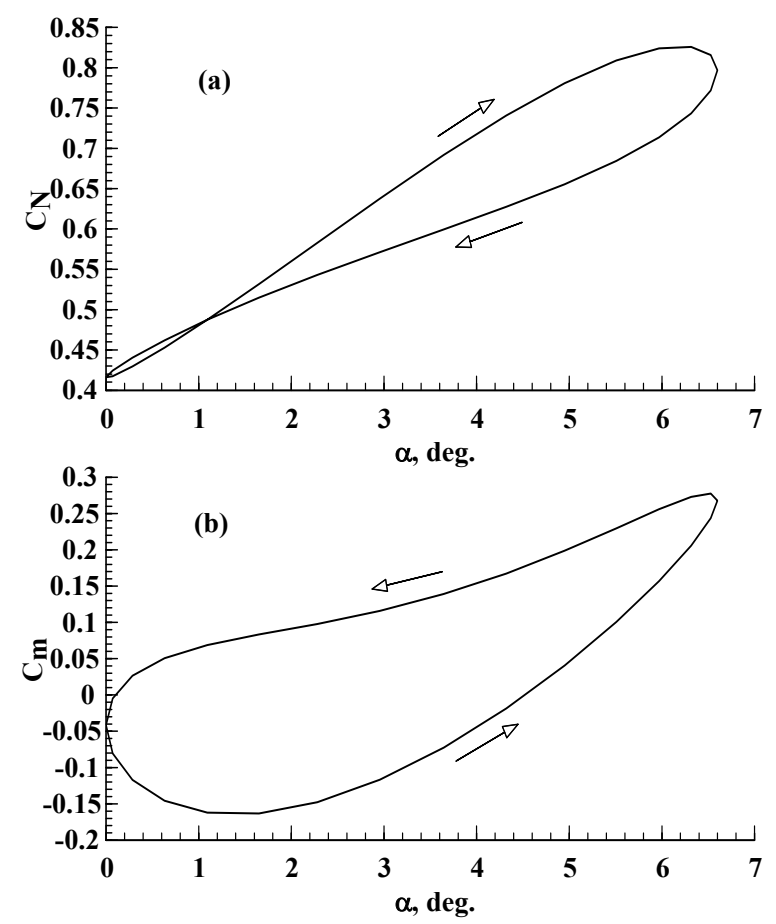

Fig. 10. Aerodynamic response due to a cosine harmonic oscillation at a reduced frequency of 0.02 in a as extracted from the fuzzy logic models. 


\subsection{Flight dynamic application}

As indicated in Introduction, the aerodynamic models generated by the FLM algorithm can serve as the forcing functions and be coupled with the dynamic equations of motion for flight simulation or flight reconstruction in accident investigation. However, it was found that the flight dynamic equations require reformulation to improve numerical damping and avoid numerical divergence (Sheu \& Lan 2011). As a result of numerical integration, the turbulent vertical wind can also be estimated from the difference in the total a as measured by the aircraft $a$-sensor and the motion-produced a by numerical integration. The numerical example presented in the quoted reference is based on the same flight data examined in this Section.

\section{Conclusions}

The main objective in this paper was to illustrate the nonlinear unsteady aerodynamic models based on the FLM technique having the capability to evaluate the variations in stability of commercial aircraft with adverse weather effects. The present FLM technique was explained in detail and verified with simple examples and wind-tunnel data. It was shown that the FLM technique was capable of handling nonlinear and unsteady aerodynamic environment exhibited for a twin-jet transport in severe atmospheric turbulence with sudden plunging motion in transonic flight. The predicted results showed that the models could produce reasonable aerodynamic coefficients and several derivatives for the assessment of stability characteristics, especially for the study of unknown factors in adverse weather conditions.

At the present time, any aircraft encountering severe atmospheric turbulence is considered uncontrollable. Since the aerodynamics represented by the fuzzy-logic models is realistic, they can be coupled with the numerical integration of flight dynamic equations to study possible improvement in controllability. However, to develop the control law, it is imperative to include the unsteady and nonlinear aerodynamic effects.

\section{References}

Chang, R. C.; Ye, C. E.; Lan, C. E. \& Guan, W. L. (2009). Flying Qualities for a Twin-Jet Transport in Severe Atmospheric Turbulence, AIAA Journal of Aircraft, Vol. 46, No. 5, pp. 1673-1680.

Gelb, A. (1982). Applied Optimal Estimation, The M. I. T. Press, Cambridge, Massachusetts, USA.

Klein, V.; Batterson, J. G. \& Murphy, P. C. (1981), Determination of Airplane Model Structure from Flight Data by Using Modified Stepwise Regression, NASA Technical Publication No. 1916, National Aeronautics and Space Administration, USA.

Lan C E \& Guan M., (2005). Flight Dynamic Analysis of a Turboprop Transport Airplane in Icing Accident, AIAA Paper 2005-5922, American Institute of Aeronautics and Astronautics, Reston, Virginia, USA. 
Lan, C. E.; Chang, R. C. \& Guan, W. L., (2006). Evaluation of Structural Integrity of Transport Aircraft Based on Flight Data," Journal of Aeronautics, Astronautics and Aviation, Series A, Vol. 38, No. 3, Sept. 2006, pp. 159-166.

Lan, C. E.; Bianchi, S. \& Brandon, J. M. (2008). Effects of Bearing Friction of a Free-to-Roll Rig on Transonic Lateral, Aerodynamics, Journal of Aircraft, Vol. 45, No. 1, Jan.-Feb. 2008, pp. 298-305.

Lan, C. E.; Bianchi, S. \& Brandon, J. M. (2008). Estimation of Nonlinear Aerodynamic Roll Models for Identification of Uncommanded Rolling Motions, Journal of Aircraft, Vol. 45, No. 3, May-June 2008, pp. 916-922.

Lan, C. E. \& Roskam, J. (2008). Airplane Aerodynamics and Performance, DAR corporation, Lawrence, KS 66044, USA.

Lee, Y. N. \& Lan, C. E. (2003). Estimation of Engine Integrity through Fuzzy Logic Modeling, AIAA paper 2003-6817, American Institute of Aeronautics and Astronautics, Reston, Virginia, USA.

Maine, R. E. \& Iliff, K. W. (1986). Application of Parameter Estimation to Aircraft Stability and Control, NASA Reference Publication No. 1168, National Aeronautics and Space Administration, USA.

Minkler, G. \& Minkler, J. (1993). Theory and Application of Kalman Filter, Magellan Book Company, Tucson, Arizona, USA.

Roskam, J. (2003). Airplane Flight Dynamics and Automatic Flight Controls, Part I, published by DAR Corporation, Lawrence, Kansas, USA.

Sheu, D. \& Lan, C. E. (2011). Estimation of Turbulent Vertical Velocity from Nonlinear Simulations of Aircraft Response, Journal of Aircraft, Vol. 48, No. 2, pp. 645-651.

Wang, Z.; Lan, C. E. \& Brandon, J. M. (1998). Fuzzy Logic Modeling of Nonlinear Unsteady Aerodynamics, AIAA Paper 98-4351, American Institute of Aeronautics and Astronautics, Reston, Virginia, USA.

Wang, Z.; Lan, C. E. \& Brandon, J. M. (1999). Fuzzy Logic Modeling of Lateral-Directional Unsteady Aerodynamics, AIAA Paper 99-4012, American Institute of Aeronautics and Astronautics, Reston, Virginia, USA.

Wang, Z.; Li, J.; Lan, C. E. \& Brandon, J. M. (2001). Estimation of Unsteady Aerodynamic Models from Flight Test Data," AIAA Paper 2001-4017, American Institute of Aeronautics and Astronautics, Reston, Virginia, USA.

Wang, Z.; Lan, C. E. \& Brandon, J. M. (2002). Estimation of Lateral-Directional Unsteady Aerodynamic Models from Flight Test Data, AIAA Paper 2002-4626, American Institute of Aeronautics and Astronautics, Reston, Virginia, USA.

Weng, C. T. \& Lan, C. E. (2008). Aerodynamic Analysis of a Landing Transport Airplane in Windshear, a monograph published by VDM Vertag Dr. Muller, Germany.

Takagi, T. \& Sugeno, M. (1985). Fuzzy identifications of systems and its applications to modeling and control, IEEE Transactions on Systems, Man and Cybernetics, Vol. SMC15 , No. 1, pp. 116-132.

Theodorsen, T. (1935). General Theory of Aerodynamic Instability and the Mechanism of Flutter, NACA Report 496, National Advisory Committee for Aeronautics, Hampton, Virginia, USA. 
Zadeh, L. A. (1973). Outline of a New Approach to the Analysis of Complex Systems and Decision Processes, IEEE Transactions on Systems, Man, and Cybernetics, Vol. SMC-3, No. 1, pp. 28-44. 


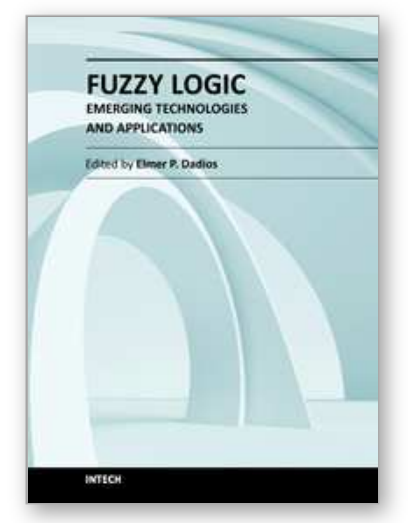

\author{
Fuzzy Logic - Emerging Technologies and Applications \\ Edited by Prof. Elmer Dadios
}

ISBN 978-953-51-0337-0

Hard cover, 348 pages

Publisher InTech

Published online 16, March, 2012

Published in print edition March, 2012

The capability of Fuzzy Logic in the development of emerging technologies is introduced in this book. The book consists of sixteen chapters showing various applications in the field of Bioinformatics, Health, Security, Communications, Transportations, Financial Management, Energy and Environment Systems. This book is a major reference source for all those concerned with applied intelligent systems. The intended readers are researchers, engineers, medical practitioners, and graduate students interested in fuzzy logic systems.

\title{
How to reference
}

In order to correctly reference this scholarly work, feel free to copy and paste the following:

C. Edward Lan and Ray C. Chang (2012). Fuzzy-Logic Analysis of the FDR Data of a Transport Aircraft in Atmospheric Turbulence, Fuzzy Logic - Emerging Technologies and Applications, Prof. Elmer Dadios (Ed.), ISBN: 978-953-51-0337-0, InTech, Available from: http://www.intechopen.com/books/fuzzy-logic-emergingtechnologies-and-applications/fuzzy-logic-analysis-of-the-fdr-data-of-a-transport-aircraft-in-atmosphericturbulence

\section{INTECH}

open science | open minds

\section{InTech Europe}

University Campus STeP Ri

Slavka Krautzeka 83/A

51000 Rijeka, Croatia

Phone: +385 (51) 770447

Fax: +385 (51) 686166

www.intechopen.com

\section{InTech China}

Unit 405, Office Block, Hotel Equatorial Shanghai

No.65, Yan An Road (West), Shanghai, 200040, China

中国上海市延安西路65号上海国际贵都大饭店办公楼 405 单元

Phone: +86-21-62489820

Fax: +86-21-62489821 
(C) 2012 The Author(s). Licensee IntechOpen. This is an open access article distributed under the terms of the Creative Commons Attribution 3.0 License, which permits unrestricted use, distribution, and reproduction in any medium, provided the original work is properly cited. 